\title{
The Effect of Recreative Purpose Modern and Traditional Archery Education on Attention Parameters in Adolescents
}

\author{
Ferhat Ustun ${ }^{1} \&$ Erdal Tasgin ${ }^{1}$ \\ ${ }^{1}$ Selcuk University, Faculty of Sports Sciences, Konya, Turkey \\ Correspondence: Erdal Tasgin, Selcuk University, Faculty of Sports Sciences, Konya, Turkey. E-mail: \\ erdaltasgin@selcuk.edu.tr
}

Received: December 27, 2019

Accepted: January 29, 2020 Online Published: January 31, 2020

doi:10.5539/jel.v9n1p244

URL: https://doi.org/10.5539/jel.v9n1p244

\begin{abstract}
This study aims to investigate the effect of recreational archery exercise on attention levels of children aged 9-13 years. 20 girls and 20 boys who participated in archery training for 4 weeks held in archery areas of special sports centers in Konya Province. The participants were given archery training 60 minutes a day, 3 days a week for 4 weeks. They participated in the attention test before and after the training.

In this study, Bourdon attention test was applied as a data collection tool. The normality test was performed to determine whether the data fit the normal distribution and the data were found to be suitable for parametric tests. In order to determine the difference between the before and after of the test, paired samples t-test was applied.

As a result of the study, it was revealed that the attention levels of the participants increased in respect of both total scores and comparisons according to variables $(\mathrm{p}<0.001)$. In this respect, it can be suggested that archery activities will have a positive effect on the attention development of 9-13 age group children. When the general literature is examined, it can be stated that attention levels of children participating in sports and exercise-based recreational activities are positively affected.
\end{abstract}

Keywords: attention, archery, recreation, sports

\section{Introduction}

More than a hundred years ago, William James wrote, "everyone knows what attention is" and he explained the attention as ability of the mind to adopt one of the objects or thoughts that are simultaneously appear in a clear manner and added that the attention was based on focusing, getting concentrated and being aware. When it comes to the concept of attention, it is explained as giving up other things to handle other things in a more effective manner (Solso et al., 2010).

Attention has been expressed as one of the most studied variables in the field of human neuroscience (Posner \& Petersen, 1990). The concept of attention is dealt with as a process of successive steps originating from different brain regions. A feature of the attention system is its limited capacity. While attention capacity exhibits differences between individuals, it may also show differences in different situations in the same individual (Kucuk et al., 2009). While passive attention is the involuntary concentration on a certain stimulus among the external stimuli around him/her without any effort. Active attention is expressed as a voluntary focus on a certain thing. For active attention; it is important that the individual to need and be interested in the stimulus that he/she required to be aware of and be alert, to concentrate his/her attention and make the necessary effort (Gaddes \& Edgell, 1994).

Many psychologists who were influenced by Freudian studies were interested in this dualist part of the mind, and the conscious and unconscious mind theory was generally accepted, although it is not objectively based. Developmental psychologists especially emphasized the attention in the process of understanding and sense-making the world of children.

According to Kinze and Roth (1991), attention-gathering skills can be improved by attention-gathering exercises. Most of the studies have included the positive results of attention-related trainings and the positive results of these studies can be mentioned even in children with attention deficit in the clinical situation. Attention and attention-gathering skills are of great importance in every period of the school years; therefore, special attention should be paid to improving attention-gathering skills starting from the pre-school period. By this way, 
educational problems that may arise in later years can be reduced (Driver \& Kula, 2016).

Attention is one of the concepts that we frequently encounter in recreational activities as in all areas of our daily lives. Although the terms concentration and attention applied in sports are used interdependently (Tuksoy Işim, 2018), the literature has defined concentration as yet the ability to act perfectly focused on the world (American Psychological Association - Division of Exercise and Sport Psychology, 2014). There are many ways to improve attention. Examples include organizing and modifying environmental support, using external aid tools, parent trainings, medications, social skills training, concentration games and psychological support. Conducted studies demonstrated that positive results can be obtained when these methods are used for attention deficit individuals.

Ozdogan (1999) states that with the development of perception, memory, motivation and 'self' and a regular training on this subject, the concentration of attention on a particular subject and the existing attention capacity can be improved with education (Kaymak, 2003). Failure to control attention affects not only school-related areas, but also success in other areas of your life. When attention control is achieved, it is ensured that the student learns effectively, be productive, behave appropriately in the education and training life and establish healthy communication. On the other hand, problems in attention control often lead to confusion in the learning process and in everyday life.

When it is examined in this context, it can be suggested that the games and exercise applications that will be given to develop attention in young ages will affect the life of the individual in the long term. It is known that sports necessarily require a demand for attention towards differentiated infrastructure (Nejati \& Nejati, 2012). Although some researchers acknowledge the importance of attention in different ways in sport, there is not much available research that can provide a specific and descriptive global theoretical framework. By the end of the first decade of this century, Boucher (2008) argued that a sufficient framework has not yet been established to examine the impact of attention on sports skills (Dos Santos et al., 2019).

In order to prevent children's perception of boredom, it is important to choose the recreational activities appropriate to the personality of the children. Most experts focused on improving attention through written and visual means. However, children may get bored of such activities after a while. Therefore, it is important to select and organize the recreational activities in relation to the development of attention skills that children may enjoy. For today's children, who are often be in the digital world, the adaptation of games on these platforms to real life seems remarkable. Studies show that target and weapon games are the most popular games. Traditional and modern archery practices are in demand today by the target group of our study. Archery is an ancient effort as human history. According to explanations of Kurat (Yonal \& Turkmen, 2017 quoting from Kurat) Archaeological findings related to the bow and arrow suggested that the archery has a very long history. The first finds related to the bow and arrow is seen in the late Paleolithic period (35000-10000 BC). The earliest arrowheads made of flint stone were found in Eastern Spain. Today, the archery branch maintains its popularity through highly developed materials. Archery, which has been used as a hunting and defense tool in history, has now been replaced by a recreational objective.

In the light of these explanations and scientific basis, our study has examined the effects of archery as a recreational activity on the attention levels of adolescent children in a scientific framework and the results have been interpreted empirically. Most of the studies in the field have focused on 'attention deficit and hyperactivity disorder' and the treatment of related disorders. However, more complex activities are required to be planned in the treatment of clinical conditions. Our study includes archery trainings performed to improve attention and points out the benefits.

\section{Material and Method}

\subsection{Research Model}

In this study, the effect of archery exercise on attention development of children during adolescence was tested. The independent variable of the research is the archery program designed to improve attention gathering skills and the dependent variable is attention scores.

This study was conducted on 40 children aged between 9 and 13 years who participated in archery training for 4 weeks in a special archery sports center in Konya province. The children were divided into 4 groups ( 2 groups of modern archery training methods, 2 groups of traditional archery training methods) and each group was divided into 10 people and was subjected to a total of 12 hours of theoretical and practical archery training for 3 days 60 minutes. Pre-test-post-test experimental pattern was used in the study. In line with this pattern, the Bourdon Attention Test Letter Form (BDT) was applied as a pretest at the beginning of the study. After a 4-week, 3 days a week, 60 min per day archery exercise training program, the final test was applied. 


\subsection{Data Collection Tool}

\section{Bourdon Attention Test (CIS)}

The most recent version of the Bourdon Attention Test was developed by Benjamin Bourdon in 1955. Bourdon test is consisting of two forms. According to Kaymak (2003), the first one is to find and mark certain letters from mixed book letters; the second one is in the form of finding and marking certain figures from mixed figures (Brickenkamp, 1975). The test requires continuous attention orientation. During the application of the test, similar operations are repeatedly applied (e.g., finding specific letters among other letters) (Wagner, 1990). The letter form consists of two pages. There are 1140 book letters in both pages. In other words, the letter form of the test consists of a total of 2280 letters. The shape form of the test consists of one page and each page has a total of 450 small figures. Participants are also asked to find certain shapes among all shapes in the shape form. There is no age limit for the application of the test. However, children need to have the ability to recognize letters. Also, there is no time limit set. In the evaluation of the test, the time, the correct number or the number of errors may be taken into consideration. The person who applied that test can make an assessment by counting how many correct answers the children have marked in a given time (e.g., 5 minutes). He/she can count how many letters or figures that children should mark correctly. Or he/she can also check whether children have marked another letter or shape other than the letters or figures that should be marked. There is no template created. The person who applied that test can determine which letters or figures should be marked and create his own template (Brickenkemp, 1975).

The Letter Form of Bourdon Attention Test was used in this study. The Bourdon Attention Test, as Wagner (1990) stated, is a well-established and frequently used test. Moreover, it is also preferred for all age groups.

\subsection{Analysis of Data}

Since it was established that it is in conformity with the normal distribution, paired t test was used in the evaluation of whether the scores of the students before and after the program show a significant difference. In the research, the level of significance was taken as $(\mathrm{P}<0.05)$.

\section{Results}

Table 1. Attention pre-post test results of children participating in archery activities

\begin{tabular}{lllll}
\hline & $\mathbf{X}$ & Ss & T & p \\
\hline Pre-test & 62.7250 & 20.88674 & -10.118 & $0.000^{* *}$ \\
Post-test & 87.3750 & 19.29220 & & \\
\hline
\end{tabular}

Note. $* \mathrm{P}<0.05$.

In Table 1, the attention scores of the children participating in recreational archery activities are given before and after the training. According to the analysis, the mean attention points of the children participating in recreational archery activity were significant in favor of the post-test $(\mathrm{p}<0.001)$.

Table 2. Pre-post test results of children participating in archery activities by gender

\begin{tabular}{llllll}
\hline Variable & & $\mathbf{X}$ & Ss & T & p \\
\hline Women & Pre-test & 60.85 & 19.21 & -7.563 & $0.000^{* *}$ \\
& Post-test & 86.05 & 19.31 & & \\
\multirow{2}{*}{ Men } & Pre-test & 64.60 & 22.77 & -7.563 & $0.000^{* *}$ \\
& Post-test & 88.70 & 19.67 & & \\
\hline
\end{tabular}

Note. $* \mathrm{P}<0.05$.

In Table 2, the attention scores of the children participating in recreational archery activities are given before and after the training according to their gender. According to the analysis, the mean attention points of the children participating in recreational archery activity were significant in favor of the post-test for both genders $(\mathrm{p}<$ $0.001)$. 
Table 3. Pre-post test results of children attending archery activities

\begin{tabular}{|c|c|c|c|c|c|}
\hline Variable & & $\mathbf{X}$ & Ss & $\mathbf{T}$ & $\mathbf{p}$ \\
\hline \multirow[t]{2}{*}{ Traditional } & Pre-test & 64.8000 & 21.26673 & -7.078 & $0.000^{* *}$ \\
\hline & Post-test & 88.3500 & 20.25177 & & \\
\hline \multirow[t]{2}{*}{ Modern } & Pre-test & 60.6500 & 20.83589 & -7.096 & $0.000^{* *}$ \\
\hline & Post-test & 86.4000 & 18.75717 & & \\
\hline
\end{tabular}

Note. $* \mathrm{P}<0.05$.

In Table 3, the attention scores of the children participating in recreational archery activities are given before and after the training according to activity that they have participated. According to the analysis, the mean attention points of the children participating in recreational archery activity were significant in favor of the post-test both for traditional archery and modern archery $(\mathrm{p}<0.001)$.

Table 4. Pre-post test results of children attending archery activities according to activity and gender variable

\begin{tabular}{lllllll}
\hline Variable & & & X & SS & t & p \\
\hline Traditional & \multirow{2}{*}{ Women } & Pre-test & 61.50 & 16.78 & -9.265 & $0.000^{* *}$ \\
& \multirow{4}{*}{ Men } & Post-test & 89.50 & 18.03 & & \\
& & Pre-test & 66.21 & 23.35 & -4.760 & $0.000^{* *}$ \\
& \multirow{3}{*}{ Modern } & Post-test & 87.85 & 21.76 & & \\
& \multirow{2}{*}{ Women } & Pre-test & 60.57 & 20.75 & -5.199 & $0.000^{* *}$ \\
& \multirow{2}{*}{ men } & Post-test & 84.57 & 20.31 & & $0.003^{* *}$ \\
& & Pre-test & 60.83 & 23.00 & -5.212 & \\
\hline
\end{tabular}

Note. $* \mathrm{P}<0.05$.

In Table 4, the attention scores of the children participating in recreational archery activities of both traditional archery and modern archery are given before and after the training according to gender variable According to the analysis, the mean attention points of the children participating in recreational archery activity were significant in favor of the post-test both for traditional archery and modern archery according to gender variable $(\mathrm{p}<0.001)$.

Table 5. Pre-post test results of children participating in archery activities by age

\begin{tabular}{llllll}
\hline Variable & & $\mathbf{X}$ & Ss & T & p \\
\hline 9-11 age & Pre-test & 55.13 & 17.84 & -9.314 & $0.000^{* *}$ \\
& Post-test & 82.55 & 19.55 & & \\
12-14 age & Pre-test & 82.72 & 14.23 & -4.835 & $0.001^{* *}$ \\
& Post-test & 100.09 & 11.65 & & \\
\hline
\end{tabular}

Note. $* \mathrm{P}<0.05$.

In Table 5, the attention scores of the children participating in recreational archery activities are given before and after the training according to age variable. According to the analysis, the mean attention points of the children participating in recreational archery activity were significant in favor of the post-test for all age groups $(\mathrm{p}<$ $0.005)$.

\section{Discussion and Conclusion}

The aim of this study was to investigate the development of attention level in children aged 9-13 years who participated in recreational archery activity. The importance and value of the studies and exercises performed to ensure the sustained attention for which we will see benefits in our school, work and daily life in the long term is supported by the literature (Ulug, 1991; Ozdemir, 2019).

The archery branch, where the shooting score depends on many variables, is also a branch that requires different parameters to be examined as well. Because this sport is not a sport that can only be played with ball, net or basket like basketball or volleyball. There are many fine-tuning points on the bow that the athlete uses. A millimeter error of these points may cause the arrows shoot by an elite athlete to go to the undesirable places on the target (Kolayis \& Mimaroglu 2008).

As a result of our study, it was observed that the attention score averages of children participating in the study in 
archery activity increased significantly after the participation. In a study conducted by Kartal et al. (2016) on athletes engaged in the fencing branch between the ages of 10-12, and study by Karaduman (2004) in which the attention levels of 4th and 5th grade students were examined, differences were observed in values taken before and after training. In the study of Tunç (2013), which examined the level of attention in children engaged in golf, it was found that the results of the pre and posttests between the experimental and control groups were consistent with our study.

In a study by Kalyon (1990) it is stated that "Sports is both beneficial and necessary for children in the age of growth in respect of both physical health and physical development as well as the formation of a good personality and good mental health". In addition, Kalyon mentioned a study conducted in France, and said that baccalaureate students divided into two groups; while reducing the theoretical course hours of one group of students, the same number of courses were maintained for the others, in the course of the study, hours of physical education and sports hours were increased for students whose course hours have been reduced. In the evaluation made at the end of the year in accordance with the study program, while the success rate was $60 \%$ in the group educating according to the former program, the success rate in the group with increased sports hours increased to $89 \%$. Therefore, it can be suggested that the increase in physical activities caused the students to focus their attention more easily on their courses and thus an increase in their success.

Ozbar and Kayapinar (2006) stated in their study that the recreational activities and movement trainings had positive effects on decreasing the number of errors and hand-eye coordination of children. In another study, which shows parallelism to our study results, Akandere et al. (2010) concluded that movement-based recreational activities performed after an 8-week study had a significant effect on children's attention duration.

Uskan (2011), in his study aimed at improving the attention skills of children between the ages of 8-10, obtained results consistent with our study results, however mentioned different research results on the results of gender-related attention development. For example; Helmke and Renkl (1993); Borchert (1998), while suggesting that girls are more successful than boys in gathering attention (cited by Kaymak, 2003); Neuhaus (2000), he emphasizes that when studies on attention are examined, girls found to have better attention gathering skills in some studies and boys found to have better attention gathering skills in other studies. This and similar studies suggest that too many factors can affect the results of studies on attention. Researchers' focus on these differences rather than similar results appears to be an important factor on the sensitivity of future studies. Our study showed that the recreational activity performed increased the attention skills of girls and boys in consistency with the general literature results.

In order to demonstrate the effect of folklore dance exercise in children with Attention Deficit and Hyperactivity Disorder (DEHB), Topcu et al. (2007) revealed a positive effect of physical activities on attention even in clinical cases. Bozan and Akay (2012) reached the similar results with our study as a result of their study on attention and as a result of the interviews, all of the students stated that they had great fun in the process, the activities were very useful, they were more careful with the training given and they were able to see the stimulants faster. Stated that they were more confident at the end of this training.

As a result, our study and most of the mentioned studies reveal that attention is a developable skill, and a situational factor that is open to influence. Therefore, attention development in children who are directed to recreational activities such as archery should be emphasized, especially during periods of rapid physical growth. Different factors can also be included in the process by keeping the duration of the training program longer in subsequent studies. The content, duration and intensity of the trainings can be programmed more extensively considering the condition and age of the subjects. It may be beneficial to apply this study to other age groups in a more comprehensive manner.

\section{References}

Akandere, M., Bastug, G., Asan, R., \& Bastug, K. (2010). The Effect of Educational Game over Attention in Children. Ovidius University Annals, Series Physical Education and Sport/Science, Movement and Health, 10(2).

American Psychological Association-Division of Exercise and Sport Psychology. (2014). Retrieved from http://www.apadivisions.org/division-47/publications/ concentration-and-attention.pdf

Barcmann, H., \& Kinzl, R. N. (1991). Aufmerksamkeit und Konzentration im Kindesalter. Berlin. Verlag Gesundhert, 224 Serten, DM 54.

Boucher, S. (2008). Attentional processes and sport performance. In T. Horn (Ed.), Advances in Sport Psychology. Champaign, Il: Human Kinetics. 
Bozan, A., \& Akay, Y. (2012). The Effect of Attention Enhancement Education on Primary School 5th Grade Students' Attention-Raising Skills. Western Anatolia Journal of Educational Sciences, 3(6).

Brickenkamp, R. (1981). Test d2. Aufmerksamkeits-belastungs-test. Göttingen: Verlag für Psychologie.

Dos Santos, J. M. F., Petrica, J. M., \& Rebelo Maia, L. A. C. (2019). Study of the attention and its importance in teaching/learning sports. Federación Española de Asociaciones de Docentes de Educación Física, 36, 457460.

Gaddes, W. H., \& Edgell, D. (1994). Learning disabilities and brain function: A neuropsychological approach. New York: Springer-Verlag. https://doi.org/10.1007/978-1-4757-2255-0

Kalyon, T. A. (1990). Sports Medicine Sportsman Health and Sports Injuries. Gata Basımevi, 123-130.

Karaduman, B. D. (2004). The Effect of Attention-Raising Education Program on Attention-Level, Self-Perception and Achievement Levels of 4th and 5th Graders of Primary Education. Ph.D. Thesis, Ankara University, Institute of Educational Sciences, Ankara.

Kartal, R., Dereceli, Ç., \& Kartal, A. (2016). Investigation of Attention Levels of Children Between 10-12 Years Old with or without Fencing Sports. Sports View: Journal of Sports and Educational Sciences, 3(2), 82-88.

Kaymak, S. (2003). The effect of attentional training program on the development of attention-gathering skills of primary and secondary school students. Ph.D. Thesis, Ankara University Institute of Social Sciences, Ankara.

Knudsen, E. I. (2007). Fundamental Components of Attention. Annu. Rev. Neurosci., 30, 57-78. https://doi.org/10.1146/annurev.neuro.30.051606.094256

Kolayis, İ. E., \& Mimaroglu, E. (2008). The effects of heart rate and aiming time on performance in Turkish National Archery Team. Journal of Human Sciences, 5(1).

Kucuk, A., Dolu, N., \& Erdogan, H. (2009). The effects of age, gender and socioeconomic level differences on attention levels of primary school students. Journal of Health Sciences, 18(1), 18-24.

Nejati, M., \& Nejati, V. (2012). Frontal Lobe Function in Chess Players. Acta Medica Iranica, 50(5), 311-314.

Ozbar, N., \& Kayapınar, C. F. (2006). Effect of Movement Education on Hand-Eye Coordination Time and Number of Errors in Preschool Children. Physical Education and Sports Science Journal, 8, 4.

Ozdemir, H. (2019). Investigation of the effects of physical activity cards and game console movement activities on attention, screen and paper reading performance in 10-11 years old children. Marmara University Institute of Educational Sciences, Department of Physical Education and Sports, Department of Sports Education, Published Master Thesis, İstanbul.

Ozdogan, B., Ak, A., \& Soyuturk, M. (2005). Teacher handbook for the education of children with attention deficit and hyperactivity/extreme mobility disorder. Ankara: Ministry of National Education.

Posner, M., \& Petersen, S. (1990) The attention system of the human brain. Annual Review of Neuroscience, 13, 25-42. https://doi.org/10.1146/annurev.ne.13.030190.000325

Solso, R. L., Maclin, M. K., \& Maclin, O. H. (2010). Cognitive Psychology. Bookstore Publications, Istanbul.

Sürücü, A., \& Kula, E. (2016). Reflections of Education and Psychology. Line Bookstore September, Konya.

Topcu, B., Yıldiz, S., \& Bilgen, Z. T. (2007). The Effect of Folklore Exercise in Children with Attention Deficit Hyperactivity Disorder. General Medical Journal, 17, 89-93.

Tunc, A. (2013). Investigation of Attention Levels of Children Playing Golf. Master Thesis, Selcuk University. Health Sciences Institute. Physical Education and Sports Department, Konya.

Turksoy, I. A. (2018). Focus on Sports. Ankara: Sports Publishing House and Bookstore.

Ulug, F. (1991). Success at School. Remzi Bookstore, Ankara.

Uskan, C. (2011). Testing the Effectiveness of a Program Based on Improving Attention Skills of 8-10 Years Old Children with Attention Deficit Disorder. Master Thesis, Istanbul

Wagner, I. (1990). Aufmerksamkeitstraining mit impulsiven kindern. Frankfurt: Dietmer Klatz.

Yonal, G., \& Turkmen, M. (2017). Archery in Turkish Cultural Life. Journal of Academic Social Research, 5(55), 523-533. https://doi.org/10.16992/ASOS.12737 


\section{Copyrights}

Copyright for this article is retained by the author, with first publication rights granted to the journal.

This is an open-access article distributed under the terms and conditions of the Creative Commons Attribution license (http://creativecommons.org/licenses/by/4.0/). 